\title{
Different Surgical Strategies for Chronic Pancreatitis SigNIFICANTLY IMPROVE LONG-TERM OUTCOME: A Comparative Single Center Study
}

\author{
P. Hildebrand ${ }^{1}$, S. Dudertadt ${ }^{2}$, R. Czymek ${ }^{1}$, F. G. Bader ${ }^{1}$, U. J. Roblick ${ }^{1}$, H.-P. Bruch ${ }^{1}$, T. Jungbluth ${ }^{1}$ \\ ${ }^{1}$ Department of Surgery and ${ }^{2}$ Department of Internal Medicine, University of Schleswig-Holstein, Campus Lübeck, Germany
}

\begin{abstract}
Objective: In general, chronic pancreatitis (CP) primarily requires conservative treatment. The chronic pain syndrome and complications make patients seek surgical advice, frequently after years of progression. In the past, surgical procedures involving drainage as well as resection have been employed successfully. The present study compared the different surgical strategies. Patients and Methods: From March 2000 until April 2005, a total of 51 patients underwent surgical treatment for CP at the Department of surgery, University of Schleswig-Holstein, Campus Lübeck. Out of those 51 patients, $39(76.5 \%)$ were operated according to the Frey procedure, and in 12 cases $(23.5 \%)$ the Whipple procedure was performed. Patient data were documented prospectively throughout the duration of the hospital stay. The evaluation of the postoperative pain score was carried out retrospectively with a validated questionnaire.

Results: Average operating time was 240 minutes for the Frey group and 411 minutes for the Whipple group. The medium number of blood transfusions was 1 in the Frey group and 4.5 in the Whipple group. Overall morbidity was $21 \%$ in the Frey group and $42 \%$ in the Whipple group. 30-day mortality was zero for all patients. During the median follow-up period of 50 months, an improvement in pain score was observed in $93 \%$ of the patients of the Frey group and $67 \%$ of the patients treated according to the Whipple procedure.

Conclusion: The results show that both the Frey procedure as well as partial pancreaticoduodenectomy are capable of improving chronic pain symptoms in CP. As far as later endocrine and exocrine pancreatic insufficiency is concerned, however, the extended drainage operation according to Frey proves to be advantageous compared to the traditional resection procedure by Whipple. Accordingly, the Frey procedure provides us with an organ-preserving surgical procedure which treats the complications of CP sufficiently, thus being an alternative to partial pancreaticoduodenectomy if there is no suspicion of malignancy.
\end{abstract}

Key words: Chronic pancreatitis - Frey procedure Whipple operation - Pain score

\section{INTRODUCTION}

Chronic pancreatitis (CP) is an inflammatory process leading to increasing and irreversible damage of parenchymal function. With an incidence of $4 / 100,000 /$ year and a prevalence of $13 / 100,000$, CP is a relatively rare disease [1]. Etiologically the majority of cases is traced back to alcohol abuse, with data varying between $55 \%$ and $80 \%$ [1-3]. The remaining percentages are classified as idiopathic, since their origin is unknown [3].

The spontaneous course with respect to pain development and the occurrence of endocrine and exocrine insufficiency is variable. The two main manifestations are recurrent attacks of abdominal pain and progressive insufficiency of endocrine and exocrine organ function. Drug therapy of CP focuses on treatment of abdominal pain symptoms, treatment of exocrine insufficiency including prevention of weight loss, stabilization of the metabolic condition, prevention of disease progression as well as prevention of complications. Finally, the psychosocial care of patients, especially considering an alcohol problem has to be considered [4]. After the disease has progressed for years or even decades, the limit of analgesia is reached in many cases and in addition to the severe long-term pain, organ complications occur which cannot be managed conservatively or interventionally. These include bile duct stenosis, duodenal stenosis, portal vein constriction with portal hypertension, formation of pseudocysts, pancreatic necroses, pancreatogenic ascites and the formation of pancreatic fistulas [5]. In almost every other patient, surgery is indicated due to the progression of the disease [6]. There is no standard surgical procedure that can always sufficiently meet all of these criteria and consider all individual special characteristics and complications associated with the disease. According to existing pathophysiological concepts, three operative methods have become most common in surgical therapy: techniques involving duct drainage, radical resective surgery and local resections. The present study documented the data of all patients operated on for CP and compared the different resective surgical strategies with respect to different parameters. 


\section{Patients And Methods}

From March 2000 until April 2005, a total of 51 patients underwent surgical treatment for CP in the Department of surgery, University of Schleswig-Holstein (Campus Lübeck). Out of those 51 patients, 39 $(76.5 \%)$ were operated on according to the Frey procedure, and in 12 cases $(23.5 \%)$, the Whipple procedure was used [7]. Only those patients were included in the evaluation for whom the diagnosis of CP was confirmed histopathologically after surgery. Decisive inclusion criteria were an inflammatory tumor of the pancreatic head and the occurrence of severe recurrent pain attacks, or organ complications. Exclusion criteria were the simultaneous evidence of malign neoplasia.

The gender distribution was 11 females and 40 males. The age span at the time of surgery was between 34 and 70 years, with an average value of 48.6 years (median: 47.5 years). Further characteristics of the study population are summarized in Table 1.

All patients were seen by gastro-enterologists, endoscopists and surgeons, who together made the indication for surgical therapy based on the clinical picture, medical history and findings. Surgery was indicated if conservative and endoscopic interventional techniques failed to yield therapeutic success or, from the very beginning, were considered unlikely to succeed. The surgical strategy was determined by the surgeon for each patient individually and based on the above criteria.
Patient data directly associated with the disease and the surgical procedure were gathered prospectively throughout the duration of the hospital stay. They include an exact medical history with respect to alcohol and analgesics, diagnoses of pancreatic insufficiency, diagnostic measures and findings and information on the course of the operation and postoperative progress.

Information on the development of pain intensity, the new occurrence of diabetes mellitus and pancreoprivic maldigestion, as well as the long-term progress of the disease were recorded retrospectively. For this purpose, 30 patients of the Frey group and 6 patients of the Whipple group were interviewed. Pain intensity was evaluated by means of a predefined pain score, which includes a visual analog pain scale and the frequency of the pain attacks as subjective parameters and the consumption of analgesics as well as the time of incapacity to work as objective parameters. The sum of the values divided by four yields the "pain score", which can assume values between 0 (no restriction) and 100 (maximum restriction). The working group of the University Medical Center in HamburgEppendorf evaluated the pain score in patients with $\mathrm{CP}$ as valid and reliable [8].

Statistical analysis: All data collected were digitalized for statistical evaluation by Excel. Data evaluation was carried out by SPSS for Windows. Dependent variables, in particular for comparison of preoperative and postoperative results, were tested for significance with the Wilcoxon rank test. For comparative quantifica-

Table 1. Clinical characteristics of the study population.

\begin{tabular}{|c|c|c|}
\hline & $\begin{array}{l}\text { Frey group } \\
\mathrm{n}=39\end{array}$ & $\begin{array}{l}\text { Whipple group } \\
\qquad \mathrm{n}=12\end{array}$ \\
\hline Age (years, $\mathrm{AV} \pm \mathrm{SD}$ ) & $46.6 \pm 9.1$ & $54.1 \pm 9.7$ \\
\hline $\operatorname{Gender}(\mathrm{m} / \mathrm{f})$ & $30 / 9$ & $10 / 2$ \\
\hline \multicolumn{3}{|l|}{ Etiology, number of patients } \\
\hline alcoholic pancreatitis & $27(69 \%)$ & $8(66 \%)$ \\
\hline pancreas divisum & $7(18 \%)$ & 0 \\
\hline idiopathic & $8(20 \%)$ & $4(33 \%)$ \\
\hline \multicolumn{3}{|l|}{ Pain for $>12$ months } \\
\hline Number of patients & $38(97 \%)$ & $10(83 \%)$ \\
\hline \multicolumn{3}{|l|}{ Period from diagnosis of $\mathrm{CP}$ until operation } \\
\hline (months, $\mathrm{AV} \pm \mathrm{SD}$ ) & $60.1 \pm 73.1$ & $48.6 \pm 71.6$ \\
\hline \multicolumn{3}{|l|}{ Weight loss $>8 \%$} \\
\hline Number of patients & $22(56 \%)$ & $6(50 \%)$ \\
\hline \multicolumn{3}{|l|}{$\begin{array}{l}\text { Increase in size of pancreatic head, } \\
\text { number of patients }\end{array}$} \\
\hline$>35 \mathrm{~mm}$ & $11(28 \%)$ & $7(58 \%)$ \\
\hline$>50 \mathrm{~mm}$ & $7(18 \%)$ & $4(33 \%)$ \\
\hline Pseudocyst, number of patients & $19(49 \%)$ & $4(33 \%)$ \\
\hline Bile duct stenosis, number of patients & $23(59 \%)$ & $7(58 \%)$ \\
\hline Duodenal stenosis, number of patients & $7(18 \%)$ & $1(8 \%)$ \\
\hline \multicolumn{3}{|l|}{ Thrombophlebitic splenomegaly } \\
\hline Number of patients & $1(3 \%)$ & $1(8 \%)$ \\
\hline \multicolumn{3}{|c|}{ Camebridge classification, number of patients } \\
\hline degree II & $4(10 \%)$ & $1(8 \%)$ \\
\hline degree III & $11(28 \%)$ & $3(25 \%)$ \\
\hline degree IV & $24(62 \%)$ & $8(67 \%)$ \\
\hline
\end{tabular}


tion, $\mathrm{p}$ values of the test variables were given. $\mathrm{P}$ values $<0.05$ are referred to as significant..

\section{RESULTS}

Average surgery time was 240 minutes for the Frey group and 411 minutes for the Whipple group. The medium number of blood transfusions was 1 in the Frey group and 4.5 in the Whipple group. 30-day mortality was zero for all patients. Further clinically relevant parameters, such as time of hospital stay, number of transfusions required and analgesics consumption are summarized in Table 2.

Overall morbidity was $21 \%$ in the Frey group and $42 \%$ in the Whipple group. Lethality was zero for all patients.

Intraoperatively, there was a surgery-induced complication with injury of the portal vein and consecutive massive transfusion in one of the patients operated on according to the Whipple procedure. After initial tamponade, the abdominal wall could definitively be closed on the second postoperative day with bleeding having stopped. Further progress was uncomplicated except for the occurrence of mild pneumonia. In the Frey group, one patient suffered an iatrogenic injury of the spleen during surgery, which was safely repaired by gluing the spleen. Further postoperative development was uncomplicated, too.

The most frequent complication developing after surgery was pneumonia, which occurred in $8 \%$ of all patients. Two patients of the Frey group had to be revised surgically due to diffuse massive bleeding and a disturbed coagulation situation as well as anastomotic insufficiency of pancreaticojejunostomy.

All further postoperative complications could be treated conservatively and are summarized in Table 3.

During the median follow-up period of 50 months, an improvement in pain score was observed in $93 \%$ of the patients of the Frey group. Out of these, 50\% reported complete freedom from pain. One patient had a preoperative and postoperative score of 0 . One patient exhibited a deterioration.

Table 2. Hospital stays, transfusions and analgesics.

\begin{tabular}{|c|c|c|}
\hline & $\begin{array}{l}\text { Frey group } \\
n=39\end{array}$ & $\begin{array}{l}\text { Whipple group } \\
\qquad \mathbf{n}=12\end{array}$ \\
\hline Hospital stay (days, AV \pm SD) & $19.6 \pm 9.4$ & $24.9 \pm 5.8$ \\
\hline Surgery time (minutes, $A V \pm S D$ ) & $240 \pm 61.8$ & $411 \pm 161.1$ \\
\hline \multicolumn{3}{|c|}{ Intraoperative transfusions (number, $\mathrm{AV} \pm \mathrm{SD}$ ) } \\
\hline Red cell concentrate & $1 \pm 1.5$ & $4.5 \pm 6.5$ \\
\hline Plasma & $1 \pm 1.8$ & $4.2 \pm 6$ \\
\hline Platelet concentrate & 0 & $0.2 \pm 0.6$ \\
\hline Intensive care unit (days, $\mathrm{AV} \pm \mathrm{SD}$ ) & $1.3 \pm 1.5$ & $2.3 \pm 3.1$ \\
\hline \multicolumn{3}{|c|}{ Consumption of analgesics (days, AV \pm SD) } \\
\hline Novalgin/Tramadol & $5.4 \pm 3.6$ & $5.8 \pm 2.6$ \\
\hline Peridural catheter anesthesia & $2.9 \pm 4.4$ & $3.2 \pm 3.2$ \\
\hline Opioids & $3.8 \pm 7.2$ & $5.5 \pm 7.8$ \\
\hline Parenteral feeding (days, $\mathrm{AV} \pm \mathrm{SD}$ ) & $2.8 \pm 2.4$ & $3.8 \pm 2.2$ \\
\hline \multicolumn{3}{|c|}{ Postoperative transfusions (number, AV $\pm \mathrm{SD}$ ) } \\
\hline Red cell concentrate & $0.8 \pm 1.9$ & $1.8 \pm 2.9$ \\
\hline Plasma & $0.8 \pm 2.2$ & $2.4 \pm 2.7$ \\
\hline Platelet concentrate & 0 & $0.1 \pm 0.3$ \\
\hline
\end{tabular}

Table 3. Postoperative complications.

\begin{tabular}{lcc}
\hline & $\begin{array}{c}\text { Frey procedure } \\
\mathbf{n}=\mathbf{3 9}\end{array}$ & $\begin{array}{c}\text { Pancreatico-duodenectomy } \\
\mathbf{n}=\mathbf{1 2}\end{array}$ \\
\hline Hemorrhage & - & - \\
$\quad$ Conservative $>3$ units of red cell concentrate & - & - \\
$\quad$ Relaparotomy & 1 & - \\
Jejunal perforation and peritonitis & 1 & - \\
Acute cardiopulmonary instability & 1 & - \\
Obstructive icterus & 1 & - \\
Pancreatic fistula & 1 & 1 \\
Ileus & - & - \\
Abscess of the abdominal wall & 1 & 2 \\
Bronchopneumonia & 2 & $5(42 \%)$ \\
Overall morbidity $(\%)$ & $8(21 \%)$ &
\end{tabular}


Table 4. Pain score (Data are medians).

\begin{tabular}{|c|c|c|c|c|}
\hline & \multicolumn{2}{|c|}{$\begin{array}{c}\text { Frey group } \\
\mathbf{n}=30\end{array}$} & \multicolumn{2}{|c|}{$\begin{array}{l}\text { Whipple group } \\
\qquad n=6\end{array}$} \\
\hline & preoperative & follow-up & preoperative & follow-up \\
\hline Visual analog pain scale & 87.5 & $0.5(\mathrm{p}<0.001)$ & 72.5 & 17.5 (n.s.) \\
\hline Frequency of pain attacks & 87.5 & $12.5(\mathrm{p}<0.05)$ & 75 & 25 (n.s.) \\
\hline Pain medication & 3 & 0 (ns) & 0 & 0 (n.s.) \\
\hline Incapacity to work & 50 & $0(\mathrm{p}=0.001)$ & 50 & 50 (n.s.) \\
\hline Pain score & 58.3 & $18.9(\mathrm{p}<0.001)$ & 48 & 23 (n.s.) \\
\hline
\end{tabular}

$67 \%$ of the patients treated according to the Whipple procedure exhibited an improvement in pain score. One patient each had a score of 0 before and after surgery; and one patient exhibited a deterioration in pain score (see Table 4 ).

Preoperative exocrine pancreatic function was limited in $50 \%$ of the 30 patients of the Frey group, and symptoms occurred under enzyme substitution. Four patients $(13 \%)$ exhibited postoperative improvement and were symptom-free without pancreatin therapy. In nine patients $(30 \%)$, exocrine pancreatic function deteriorated. Postoperatively, $67 \%$ of the patients received enzyme substitution as a therapy for exocrine pancreatic insufficiency. Out of those, 55\% (11 of the $20 \mathrm{pa}-$ tients) were symptom-free, while $45 \%$ continued to exhibit clinical symptoms. $20 \%$ of the patients remained without pancreoprivic maldigestion both before and after surgery.

In the Whipple group, four patients (67\%) had symptomatic exocrine pancreatic insufficiency before the operation. In one patient, a new disturbance of pancreatic function requiring substitution therapy occurred postoperatively. Out of the five patients $(83 \%)$ who suffered from exocrine pancreatic insufficiency postoperatively, three were symptom-free under enzyme therapy.

A total of 5 patients $(17 \%)$ of the Frey group had insulin-requiring diabetes mellitus before surgery. Whereas after the operation, two patients exhibited a clear improvement of the diabetic metabolic condition (change of therapy of one patient each to dietetic treatment and drug therapy), glucose metabolism considerably deteriorated in five patients. Three of the five patients developed newly occurring insulin-requiring diabetes, and two further patients who had preoperatively undergone drug therapy were required to change to insulin after surgery. Postoperatively, 27\% of the patients suffered from insulin-requiring diabetes mellitus.

In the Whipple group, one patient suffered from insulin-requiring diabetes mellitus before surgery. Postoperatively, there was a significant deterioration in the diabetic metabolic condition in three patients, who had to switch to insulin therapy. In two of these cases, diabetes mellitus had been managed by diet and in one case by drug therapy before. Postoperatively, four of the six patients $(67 \%)$ had insulin-requiring diabetes.

Preoperatively, $75 \%$ of the patients of the Frey group and $58 \%$ of the patients of the Whipple group lost an average of 10.9 or $14.4 \mathrm{~kg}$ of weight, respec- tively. Postoperatively, $50 \%$ of the patients of the Frey group and $33 \%$ of the patients of the Whipple group exhibited an average weight gain of 6.5 or $8 \mathrm{~kg}$, respectively.

\section{Discussion}

CP primarily always is a disease which requires conservative treatment. Recent studies on long-term progression, however, have shown that the majority of patients with CP will not become pain-free even after the disease has progressed for more than 10 years. The chronic pain syndrome and complications such as bile duct stenosis, duodenal, pancreatic duct or vascular obstruction or symptomatic pancreatic pseudo-cysts frequently require surgical intervention during progression. In the past, surgical procedures involving drainage as well as resection have been employed successfully.

One of the negative aspects of bypass surgery is the fact that malignancy cannot be safely excluded. Another factor is the lower frequency of long-term freedom from pain of only 0 to $42 \%$ after an average of 41 months $[8,9]$. Complications associated with a tumor, such as duodenal or bile duct stenoses, cannot be treated sufficiently by this procedure, either [10]. This procedure is only efficient if there is a single obstruction between the pancreatic duct and the ampulla vateri.

Even today, partial pancreaticoduodenectomy according to Whipple is considered the standard therapy for unclear tumors of the pancreatic head [11]. Drawbacks of the operation are, in addition to a high morbidity rate of up to $50 \%$ [12], the frequent occurrence of postoperative diabetes and maldigestion after pancreatectomy [11]. Loss of disease-free neighboring organs is an additional disadvantage of partial pancreatectomy [12] and frequently leads to dumping complaints and episodes of cholangitis [11]. The pyloruspreserving modification of the traditional Whipple procedure failed to lead to a considerable improvement of the adverse aspects [12].

The Frey procedure combines a longitudinal pancreaticojejunostomy with longitudinal opening of the pancreatic duct and a wedge-shaped local resection of the pancreatic head [13]. This method is also referred to as "extended drainage procedure" [12], which combines the advantages of the two fundamental surgical principles, drainage and resection. This method is considered to be simpler and faster than pancreatic head 
Table 5. Comparison of study results relating to the Frey procedure and partial pancreaticoduodenectomy.

\begin{tabular}{|c|c|c|c|c|c|c|}
\hline & $\begin{array}{c}\text { Follow-up in } \\
\text { months }\end{array}$ & $\begin{array}{l}\text { Number of } \\
\text { patients }\end{array}$ & $\begin{array}{l}\text { Freedom } \\
\text { from pain }\end{array}$ & $\begin{array}{l}\text { Significant } \\
\text { improvement }\end{array}$ & $\begin{array}{l}\text { Newly } \\
\text { acquired, } \\
\text { insulin- } \\
\text { requiring } \\
\text { diabetes }\end{array}$ & $\begin{array}{c}\text { Newly } \\
\text { acquired } \\
\text { exocrine } \\
\text { insufficiency }\end{array}$ \\
\hline \multicolumn{7}{|l|}{ Frey procedure } \\
\hline Own results & 50 & 30 & $50 \%$ & $43 \%$ & $17 \%$ & $30 \%$ \\
\hline Frey, 1994 & 37 & 50 & $34 \%$ & $40.50 \%$ & $11 \%$ & $11 \%$ \\
\hline Izbicki, 1995 & 18 & 22 & $89 \%$ & - & - & $10 \%$ \\
\hline Izbicki, 1997 & 30 & 36 & $92 \%$ & - & $3 \%$ & $3 \%$ \\
\hline Izbicki 1998 & 24 & 31 & $90 \%$ & - & - & $3 \%$ \\
\hline \multicolumn{7}{|c|}{ Pancreaticoduodenectomy } \\
\hline Own results & 50 & 6 & - & $67 \%$ & $50 \%$ & $17 \%$ \\
\hline Klempa, 1995 & 36 & 30 & $60 \%$ & $10 \%$ & $30 \%$ & $80 \%$ \\
\hline Izbicki, 1998 & 24 & 30 & $87 \%$ & - & $9.70 \%$ & $22.60 \%$ \\
\hline Witzigmann, 2002 & 18 & 20 & $40 \%$ & $20 \%$ & $10 \%$ & no data \\
\hline
\end{tabular}

resection according to Beger, because the pancreatic head is not detached and thus there is no danger of hemorrhages from the portal vein $[13,14]$. Advantages of this organ-preserving operative technique are said to be long-term freedom from pain, low morbidity and mortality compared to the Whipple procedure and a low rate of newly occurring diabetes mellitus [10].

The results of our own and other studies show that both the Frey procedure as well as partial pancreaticoduodenectomy are capable of improving chronic pain symptoms in CP. As far as later endocrine and exocrine pancreatic insufficiency is concerned, however, the extended drainage operation according to Frey proves to be advantageous compared with the traditional resection procedure (Table 5).

In this context, the preservation of the gastroduodenal passage and bile duct continuity seems to be of decisive importance for the regulation of exocrine secretion efficiency of the pancreas and glucose metabolism [15]. In the Frey group, two thirds of the patients were completely rehabilitated after surgery, both occupationally and socially. Patients with preoperative organ complications, such as duodenal stenosis and a tumor of the pancreatic head, postoperatively were free from symptoms in $90 \%$ of the cases. Partial pancreaticoduodenectomy is the most frequently applied surgical method in patients with associated complications in neighboring organs $[10,12]$. It not only leads to far longer surgery, intensive care monitoring and hospitalization times, but also necessitates blood transfusions more frequently and results in a twice as high morbidity rate compared to the Frey patients (Table 6). Occupational and social rehabilitation is limited. Under these circumstances, the radical nature of the surgical procedure must be called into question if chronic inflammatory disease is benign, particularly since our data confirm the experience that the aims of therapeutic intervention in CP are safely achieved by the Frey procedure.

The comparison of study results is difficult, not only because there is no agreement on the assessment of pain intensity, but also due to ambiguous diagnosis criteria. In our patient group, it leads to an unexpectedly high new manifestation rate of exocrine pancreatic insufficiency of $30 \%$. A diagnosis of CP is made clinically and based on medical history, and frequently only after episodes of complaints have recurred for

Table 6. Comparison of study results relating to the Frey procedure and to partial pancreaticoduodenectomy.

\begin{tabular}{|c|c|c|c|c|}
\hline $\begin{array}{l}\text { Medium } \\
\text { surgery time } \\
\text { in minutes }\end{array}$ & $\begin{array}{l}\text { Hospital } \\
\text { stay in days }\end{array}$ & $\begin{array}{l}\text { Morbidity } \\
\text { in } \%\end{array}$ & $\begin{array}{c}\text { Transfusion, } \\
\text { number as } \\
\text { median value }\end{array}$ & $\begin{array}{l}\text { Weight gain, } \\
\text { number in } \%\end{array}$ \\
\hline
\end{tabular}

\section{Frey procedure}

Own results

Frey, 1994

Izbicki, 1995

Izbicki, 1997

Izbicki, 1998

$\begin{array}{cr}240 & 19 \\ - & 18 \\ 289 & - \\ 284 & - \\ 245 & -\end{array}$

19.6

18.7

$-$

- $19 \%$

$\begin{array}{ccc}21 \% & 1 & 50 \% \\ 22 \% & - & 64 \% \\ 9 \% & 2.5 & 77 \% \\ 22 \% & 1.7 & 69 \% \\ 19 \% & 1.2 & 81 \%\end{array}$

\section{Pancreaticoduodenectomy}

Own results

Klempa, 1995

Izbicki, 1998

$\begin{array}{cc}411 & 24.9 \\ - & 21.7 \\ 328 & -\end{array}$

$42 \%$
$43 \%$
$53 \%$
$33 \%$

$40 \%$ 
years. The situation is similar for the diagnosis of exocrine pancreatic insufficiency, although specific and sensitive functional tests exist for the confirmation of a disturbance of pancreatic function. Since in CP, symptomatic maldigestion as well as confirmed exocrine insufficiency represent an indication for pancreatin therapy [16], the complex functional tests hardly bear any therapeutic consequence and are frequently not carried out at all - this also applied to our patients. Although visual diagnosis of steatorrhea strongly depends on the experience of the observer, it is unacceptably bad, especially if characteristics are not very pronounced or the quantity of stools is small [17]. Therefore, the secretin-pancreozymin test is considered the gold standard in the diagnosis of exocrine pancreatic insufficiency [18].

The ratio of pancreatic insufficiency in fact newly occurring postoperatively can only be determined if an adequate diagnosis was made before surgery [19]. This ratio is also erroneous and too high if postoperative enzyme therapy is conducted prophylactically and without confirmation of the diagnosis. However, a placebo-controlled study substantiated the necessity and efficiency of long-term pancreatin therapy initiated directly after surgery for patients operated on according to the Frey procedure [20].

A comparison between patients having undergone surgery and patients with a conservative therapeutic regime is unreliable because the former were in a worse condition preoperatively and progression of the disease was expected. Nevertheless, the results of such a comparative study [21] indicate no major differences in pain development, and overall freedom from pain amounts to $35 \%$ after an average disease duration of 11.2 years. After a median disease progression time of 9.7 years, $50 \%$ of our patients were completely pain-free. Nevertheless, therapeutic caution is not justified in long-term morphine therapy [16]. Therapy of long-term severe pain symptoms remains the domain of surgery [22].

In summary, for patients with chronic pancreatitis, freedom from pain as well as metabolic changes are of decisive importance. Compared with other traditional surgical techniques, Frey's drainage procedure with the additional local resection of the pancreatic head seems to offer advantages with respect to long-term freedom from pain and the low risk of a surgery-induced deterioration of pancreatic function. From our point of view, Frey's procedure can thus be recommended as a new standard method for surgical therapy of CP. This method provides us with an organ-preserving surgical principle for treating the complications of CP without deteriorating the situation for the patient.

\section{REFERENCES}

1. Etemad B, Whitcomb DC: Chronic pancreatitis: Diagnosis, classification and new genetic developments. Gastroenterology. 2001; 120: 682-707

2. Foitzik Th, Buhr HJ: New aspects in the pathophysiology of chronic pancreatitis. Chirurg 1997; 68: 855-64

3. Lankisch PG, Assmus C, Maisonneuve P, Lowenfels AB: epidemiology of pancreatic diseases in Lüneburg County. Pancreatology 2002; 2: 469-77

4. Schneider, M.V. Singer: Chronic pankreatitis: Conservative therapy; Praxis 2005; 94: 831-38
5. Schoenberg MH, Schlosser W, Beger HG: Surgical therapy of chronic pancreatitis. Dt Ärztebl 1999; 96: 625-30

6. Ammann RW, Muellhaupt B, Zürich Pancreatitis Study Group: The natural history of pain in alcoholic chronic pancreatitis. Gastroenterology 1999; 116: 1132-40

7. Frey CF, Suzuki M, Isaji S, Zhu Y: Pancreatic resection for chronic pancreatitis. Surg Clin North Am 1989; 69: 499-528

8. Bloechle C, Izbicki JR, Knoefel WT, Kuechler T, Broelsch CE: Quality of Life in chronic pancreatitis - results after duodenum-preserving resection of the head of the pancreas. Panceas 1995; 11: 77-85

9. Harrison JL, Prinz RA: The surgical management of chronic pancreatitis: pancreatic duct drainage. Adv Surg 1999; 32: 1-21

10. Izbicki JR, Bloechle C: Drainage operation as therapeutic principle of surgical organ saving treatmant of chronic pancreatitis. Chirurg 1997; 68 865-73

11. Beger HG, Schoenberg MH, KH Link, Safi F, Berger D: Duodenum-preserving pancreatic head resection: a standard method in chronic pancreatitis. Chirurg 1997; 68: 874-80

12. Izbicki JR, Bloechle C, Knoefel WT, Kuechler T, Binmoeller KF, Soehendra N, Broelsch CE: Drainage versus resection in surgical therapy of chronic pancreatitis of the head of the pancreas: a randomized study. Chirurg 1997; 68: $369-77$

13. Ho HS, Frey CF.: The Frey procedure: local resection of pancreatic head combined with lateral pancreaticojejunostomy. Arch Surg 2001; 136: 1353-8

14. Frey CF, Amikura K: Local resection of the head of the pancreas combined with longitudinal pancreaticojejunostomy in the management of patients with chronic pancreatitis. Ann Surg 1994; 220: 492-507

15. Klempa I, Spatny M, Menzel J, Baca I, Nustede R, Stöckmann F, Arnold W:Pancreatic function and quality of life after resection of the head of the pancreas in chronic pancreatitis. Chirurg 1995; 66: 350-9

16. Hammer J, Hammer HF, Schöfl R: Chronic Pancreatitis und Pancreas insufficiency - Guidelines for Diagnostic and Therapy. J Gastroenterol Hepatol Erkr 2006; 1: 7-11

17. Lankisch PG, Dröge M, Hofses S, König H, Lembcke B: Steatorrhoea: you cannot trust your eyes when it comes to diagnosis. The Lancet 1996; 347: 1621

18. Lankisch PG: Diagnosis of chronic pancreatitis. The Lancet 1998; 351: 599

19. Frey CF, Braasch J: Surgical Management of Chronic Pancreatitis: The Need to Improve Our Observations and Assessment of Results. Am J Surg 1984; 147: 189-90

20. Van Hoozen CM, Peeke PG, Taubeneck M, Frey CF, Halsted CH: Efficacy of enzyme supplementation after surgery for chronic pancreatitis. Pancreas. 1997; 14: 174-80

21. Lankisch PG, Löhr-Pappe A, Otto J, Creutzfeldt W: Natural course in chronic pancreatitis. Digestion 1993; 54: 148-55

22. Lankisch PG: Chronic Pancreatitis -still a surgical disease? Chirurg 1997; 68: 851-4

Received: December 19, 2009 / Accepted: March 16, 2010

Address for correspondence:

PD Dr. med. Philipp Hildebrand

University of Schleswig-Holstein, Campus Lübeck

Department of Surgery

Ratzeburger Allee 160

23538 Lübeck

Germany

Phone: +494515006348

Fax: +494515002069

E-mail: philipphildebrand@yahoo.com 